\title{
QUEEN'S
UNIVERSITY
BELFAST
}

\section{Calcified nodules in retinal drusen are associated with disease progression in age-related macular degeneration}

Tan, A. C. S., Pilgrim, M. G., Fearn, S., Bertazzo, S., Tsolaki, E., Morrell, A. P., Li, M., Messinger, J. D., DolzMarco, R., Lei, J., Nittala, M. G., Sadda, S. R., Lengyel, I., Freund, K. B., \& Curcio, C. A. (2018). Calcified nodules in retinal drusen are associated with disease progression in age-related macular degeneration. Science Translational Medicine, 10(466), [eaat4544]. https://doi.org/10.1126/scitranslmed.aat4544

Published in:

Science Translational Medicine

Document Version:

Peer reviewed version

Queen's University Belfast - Research Portal:

Link to publication record in Queen's University Belfast Research Portal

Publisher rights

(c) 2018 The Authors. This work is made available online in accordance with the publisher's policies. Please refer to any applicable terms of use of the publisher.

\section{General rights}

Copyright for the publications made accessible via the Queen's University Belfast Research Portal is retained by the author(s) and / or other copyright owners and it is a condition of accessing these publications that users recognise and abide by the legal requirements associated with these rights.

Take down policy

The Research Portal is Queen's institutional repository that provides access to Queen's research output. Every effort has been made to ensure that content in the Research Portal does not infringe any person's rights, or applicable UK laws. If you discover content in the Research Portal that you believe breaches copyright or violates any law, please contact openaccess@qub.ac.uk. 


\section{Calcified nodules in retinal drusen are associated with progression in age-related} macular degeneration

Authors: Anna C.S. Tan, ${ }^{\# 1,2,3,4}$ Matthew G. Pilgrim, ${ }^{\# 5,6}$ Sarah Fearn, ${ }^{7}$ Sergio Bertazzo, ${ }^{8}$ Elena Tsolaki, ${ }^{8}$ Alexander P. Morrell, ${ }^{9}$ Miaoling Li, ${ }^{10}$ Jeffrey D. Messinger, ${ }^{10}$ Rosa Dolz-Marco,,${ }^{1,2}$ Jianqin Lei, ${ }^{11}$ Muneeswar G. Nittala, ${ }^{11}$ Srinivas R. Sadda, ${ }^{11,}{ }^{12}$ Imre Lengyel, ${ }^{\dagger * 5,13} \mathrm{~K}$. Bailey Freund, ${ }^{* 1,2,14}$ and Christine A. Curcio *10

\section{Affiliations:}

1. Vitreous, Retina Macula, Consultants of New York, New York, NY, USA 10022

2. LuEsther T Mertz Retinal Research Center, Manhattan, Eye, Ear and Throat Hospital, New York, NY, USA 10075

3. Singapore National Eye Center/ Singapore Eye Research Institute Singapore, Singapore, Singapore 168751

4. Duke-NUS Singapore, Singapore 168751

5. UCL Institute of Ophthalmology, 11-43 Bath Street, London, EC1V 9EL, UK

6. Division of Biomaterials and Tissue Engineering, UCL Eastman Dental Institute, University College London, London, WC1X 8LD, UK

7. Department of Materials, Imperial College London, London, SW7 2AZ, UK

8. Department of Medical Physics \& Biomedical Engineering, U niversity College London, Malet Place, Engineering Building, London WC1E 6BT, UK

9. Material Physics, Aston University, Aston Express Way, Birmingham, B4 7ET, UK

10. Department of Ophthalmology, School of Medicine, University of Alabama at Birmingham, Birmingham, AL, USA 32594-0019

11. Doheny Image Reading Center, Doheny Eye Institute, Los Angeles, California, USA 90033

12. Department of Ophthalmology, David Geffen School of Medicine at UCLA, Los Angeles, California, USA 90095.

13. Centre for Experimental Medicine, School of Medicine, Dentistry and Biomedical Science, Queen's University Belfast, Belfast, BT9 7BL, UK

14. Department of Ophthalmology, New York University Langone School of Medicine, New York, NY 10016 \# These authors contributed equally to this work; * co-senior; ${ }^{\dagger}$ corresponding author 
Correspondence: Imre Lengyel, PhD; Centre for Experimental Medicine; School of Medicine, Dentistry and Biomedical Science; Queen's University Belfast, Belfast, BT9 7BL UK Queen's University Belfast; Tel: +44 (0) 289097 6027; (E): i.lengyel@ucl.ac.uk

\section{One Sentence Summary: Clinical and nano-analytical imaging identified large}

hydroxyapatite nodules in drusen as indicators of risk for progression to advanced age-related macular degeneration.

\section{ABSTRACT}

Drusen are lipid-, mineral- and protein-containing extracellular deposits that accumulate between the basal lamina of the RPE and Bruch's membrane (BrM). Macular drusen are a defining feature of age-related macular degeneration (AMD), a prevalent sight-threatening disease of older adults. In AMD patients, optical coherence tomography occasionally shows heterogeneous internal reflectivity within soft drusen (HIRD) associated with substantially increased risk of incident advanced AMD. Here, we replicated the results in an independent patient cohort, showing that HIRD increased risk over 1 year of follow-up. We further showed with multimodal imaging in an additional cohort that the retinal pigment epithelium (RPE) overlying HIRD is hypoautofluorescent. Based on known pathology studies, we hypothesized that multilobular refractile nodules in drusen might be responsible for HIRD. Further, knowing that drusen contained mineralized spherules, we hypothesized that nodules are also mineralized. Using nano-analytical imaging techniques, we confirmed that hydroxyapatite deposits are present in nodules, as they are in spherules and BrM plaques. However, nodules uniquely lack magnesium and represent polycrystalline hydroxyapatite, whereas spherules diffract as single crystal whitlockite, and plaques are amorphously crystalline. Extracellular mineralization together with clinical hypoautofluorescence indicate the agonal state of the RPE. 
These findings underlie the nodules' significance as progression indicators and may help direct therapeutic strategies toward early disease stages. 


\section{Introduction}

Globally, age-related macular degeneration (AMD) is a prevalent cause of legal blindness in the elderly (1). Although effective therapies exist for the neovascular form of advanced AMD (2), there is no approved treatment for geographic atrophy (GA) (3), the advanced form of AMD defined by focal atrophy of the retinal pigment epithelium (RPE) in the setting of extracellular deposits called drusen. Drusen, which occur early in AMD, are lipid-, $(4-8)$ mineral- $(9,10)$ and protein- (11-14) containing extracellular deposits that accumulate between the basal lamina of the retinal pigment epithelium (RPE) and Bruch's membrane $(\mathrm{BrM})(15,16)$. RPE cells support overlying photoreceptors and underlying choroidal vasculature, of which BrM, a layered extracellular matrix, is the innermost component.

Clear ocular optics and sophisticated cellular-level clinical imaging techniques allow detailed study of AMD microarchitecture in vivo $(17,18)$. Indicators of disease severity and therapeutic efficacy might help the design and evaluation of clinical trials and the identification of targetable biological processes to both prevent progression and treat advanced AMD. Imaging methodologies based on high-speed optical coherence tomography (OCT) are being used to define indicators that predict an increased risk of progression in eyes with intermediate AMD (19). Three distinctive OCT reflectivity signatures appear in eyes with GA: 1) small hyperreflective dots within drusen (20), 2) heterogeneous internal reflectivity within drusen (HIRD) $(21,22)$, and 3) hyperreflective lines near $\operatorname{BrM}(23,24)$. Of these, HIRD has been shown to be associated with increased risk for progression to advanced AMD (21). The composition of HIRD and why they are hyporeflective are not yet defined.

At least three forms of calcifications (mineral depositions) capable of generating OCT reflectivity have been identified in AMD-affected tissues by various techniques (Table S1), including light microscopy for refractility, histochemical stains for phosphate and hydroxyapatite (HAP), and 
elemental and diffraction analysis for minerals. Drusen contain small spherules that are refractile, histochemically positive for phosphates and $\operatorname{HAP}(25,26)$, and exhibit $\operatorname{HAP}$-like patterns when interrogated by synchrotron $\mu$-X-ray diffraction $(9,10)$. BrM plaques contain phosphate by histochemistry (27) and calcium by elemental analysis $(26,28)$, but in vivo reflectivity characteristics are unknown. Nodules are large, refractile, and multi-lobed (20) positive for phosphates (29) and currently lack both a definitive mineral composition and an imaging signature. Based on spherules and BrM plaques, we expect that nodules also contain calcium phosphate.

Materials science has contributed important new concepts about the composition and formation of early bone development, ectopic calcification in cardiovascular disease $(30,31)$, and HAP spherules in drusen (20). We reasoned that this approach could also reveal composition and suggest formative processes of HIRD and plaques. Using a combination of clinical, histopathologic, and molecular imaging techniques, we determined that the HIRD progression indicator is a nodule, that is, a crystalline calcium phosphate mineral molecularly distinct from both spherules and plaques. Based on our results, we propose that multi-modal imaging staging system evaluating the composition of drusen might be useful for determining the risk of progression in AMD.. 


\section{RESULTS}

Multi-modal imaging appearance of potentially calcified structures

To define and contextualize OCT signatures in human patients with AMD, we used multimodal clinical imaging of $97 \mathrm{HIRD}$ in Cohort 1. Cohort 1 was comprised of 21 eyes (HIRD per eye, mean 4.6, range 1-15) of 17 AMD patients (6 men, 11 women, age at baseline $75.9 \pm 10.4$ years, range 58-94) for a mean of 6.17 years (range 3.2-7.5 years; mean number of consecutive OCT scans per eye, 22.9, range 10-62; total of 1198 B-scans) (Original data is in Dataset S1).

HIRD were identified on OCT within RPE elevations by reference to previous descriptions. They were occasionally associated with hyperreflective interior substructures (Fig. 1 A: red arrow), non-refractile appearance on color fundus photography (CFP) (Fig. 1 B: red arrow), isoautofluorescent in an area of confluent hypoautofluorescence on fundus autofluorescence (FAF) (Fig. 1 C: red arrow) and non-reflective on near-infrared reflectance imaging (NIR) (Fig. 1 D: red arrow). A thickened hyperreflective cap (Fig. 1 A: pink arrowhead) that is non-refractile on CFP (Fig. 1 B: pink arrowhead) appears mildly hypoautofluorescent with a hyperautofluorescent ring on FAF (Fig. 1 C: pink arrowhead), and is mildly hyperreflective on NIR (Fig. 1 D: pink arrowhead). Hyperreflective dots within HIRD (Fig. 1 A, green circle) are visible as glistening dots on CFP (Fig. 1 B, green circle), occasionally hidden by a hyperreflective cap (Fig. 1 A, pink arrowhead), undetectable on FAF (Fig. 1 C, green circle), and hyperreflective on NIR (Fig. 1 D, green circle). Hyperreflective lines that are parallel to and sometimes indistinguishable from BrM (Fig. 1 A, blue arrowhead) are glistening on CFP (Fig. 1 B, blue arrowhead), hypoautofluorescent on FAF (Fig. 1 C, blue arrowhead), and highly reflective on NIR (Fig. 1 D, blue arrowhead). During the follow-up period, the number of lesions visible on CFP, NIR, and FAF all increased (Fig. S1, p<0.05 Fisher exact test). Together HIRD 
and the overlying reflective caps were independently described in OCT as hyperreflective pyramidal structures (22) and C(onical)-type drusen (32).

HIRD association with progression to advanced AMD

To understand the prognostic potential of HIRD for advanced AMD and determine if the original finding of progression risk (21) could be replicated, we performed a 12-month long longitudinal observation study. A total of 138 eyes from 138 patients in Cohort 2 (mean age 80.2 years \pm 7.8; range, 63-96 years, 55 males and 76 females, original data is in details in Dataset S2) with intermediate AMD and sequential OCT data were analyzed for the presence of HIRD on dense volume OCT scans. Among these 138 eyes, 62 (45\%) had evidence of at least one HIRD on OCT. Fifty-five (40\%) progressed to advanced AMD (defined as neovascular AMD or GA) within the next 12 months, including 33 which progressed to GA only, 14 which progressed to CNV only, and 8 which progressed to both atrophy and CNV. HIRD were significantly and independently associated with progression to advanced AMD at 12 months with an odds ratio of 6.36 (95\% Cl: 2.99-13.53; $\mathrm{P}<0.001)$, suggesting that HIRD might have prognostic value for neovascular AMD and GA.

\section{Imaging-histology correlation of HIRD}

To link OCT imaging characteristics with molecular analysis, we correlated OCT with histology in eyes of deceased eye donors. Case 1 was the left eye of an 86 year old woman with GA, recovered 4 months after the last clinic visit (Fig. 2 A,B). HIRD on OCT corresponded to a multilobular nodule amidst typical soft druse contents, overlaid by RPE and thick basal laminar deposit (BLamD, thickened RPE basement membrane) (Fig. 2 C,D). Case 2 was the left eye of a clinically undocumented donor with macroscopically visible GA that was imaged with ex vivo OCT (Fig. 2 E, F). HIRD corresponded to a central nodule surrounded by proteinaceous material, covered by thin BLamD, absent RPE (Fig. 2 G) and atrophied photoreceptors (Fig. 2 
H).

To derive a plausible pathogenic sequence for HIRD (Fig. 3), we examined images from an online resource for AMD histopathology (http://projectmacula; $(n=139 ; 26$ with early AMD, 13 with GA, 40 with neovascular AMD, 52 with healthy maculas, and 8 with other or unknown characteristics; mean age 82.8 years, standard deviation 8.4 years; all white; 89 female, 50 male). We found that large nodules and isolated RPE cells appeared only within the original lipidic contents of soft drusen, often surrounded by a fibrous material (Fig. 3 A, B). As RPE coverage gradually decreased (Fig. 3 C, D), and BLamD persisted after RPE loss (Fig. 3 E-G), contents of individual drusen were replaced by nodules, as previously described (33) (Fig. 3 CG). Drusen in Fig. 3 C-G have both nodules and spherules, always distinct from BrM. In contrast, BrM had refractile plaques distinct from structures in drusen (Figs. 2 G, 3 A-G). Altogether, this analysis suggests that nodules might play a major role in HIRD.

\section{Composition of nodules, spherules, and BrM plaques}

To investigate nodule composition we utilized scanning electron microscopy (SEM), energy dispersive x-ray spectroscopy (EDX), HAP specific fluorescent staining, secondary ion mass spectrometry (SIMS), synchrotron x-ray fluorescence and transmission electron microscopyselected area electron diffraction (TEM-SAED). Table $\mathbf{S 2}$ shows that all techniques were applied to samples of at least two different donors.

We analyzed two histologically verified AMD cases. The first presented a serous RPE detachment and RPE atrophy and exhibited cloud-like pearly drusen and conventional soft drusen (Fig. S2) (34). The second AMD case possessed refractile nodules within microdissected macular soft drusen that were also amenable to analysis (35). In both cases, nodules, spherules and plaques were first examined using SEM. Nodules (Fig. 4 A, Fig. S3) and spherules (Fig. 4 B) were readily visible on scanning electron micrographs due to their distinct 
morphology; however, plaques were not (Fig. 4 C, D). Plaques were identifiable only by backscattered scanning electron microscopy, which showed dense material within BrM, likely mineralization (Fig. S4).

Nodules (Table S2) were subsequently examined with EDX spectroscopy. One discrete peak corresponding to phosphorus $(\mathrm{P})$ and calcium $(\mathrm{Ca})$ were clearly identifiable on spectra obtained from spherules (Fig. 4 L), plaques (Fig. 4 M), and nodules (Fig. 4 K). This suggests all 3 lesions are composed of an inorganic calcium phosphate. Peaks corresponding to carbon (C), oxygen $(\mathrm{O})$, and sodium $(\mathrm{Na})$ emanating from the mineralized lesions as well as from the surrounding organic soft tissues were also present (Fig. 4 K, L, M). A small discrete peak for magnesium $(\mathrm{Mg})$ was also present on spectra from spherules and plaques; however, this peak was absent for nodules (Fig. 4 K, L, M). To confirm $\mathrm{Ca}$ and $\mathrm{P}$ as major components, we mapped the $\mathrm{Ca}$ and $\mathrm{P} \mathrm{X}$-ray emissions. $\mathrm{Ca}$ and $\mathrm{P}$ were always enriched within nodules, spherules, and plaques, compared to the surrounding tissues (Fig. 4 E, H, Nodule; Fig. 4 F, I, Spherule; Fig. 4 G, J, BrM plaque).

Macular tissue with nodules, previously interrogated by ex vivo color imaging (26), was also investigated with micro-focus synchrotron $\mathrm{x}$-ray fluorescence and we confirmed the presence of Ca (Fig. S5 C).

Isolated nodules etched of resin and sectioned to $2 \mu \mathrm{m}$ thickness were also characterized using time of flight-secondary ion mass spectrometry (TOF-SIMS) (Table S2). Typical ionic signatures including 39.9, 55.9, 102.9, 158.9, 174.9 and $230.8 \mathrm{~m} / \mathrm{z}$ corresponding to [Ca+], [CaO+], $\left[\mathrm{CaPO}_{2}^{+}\right],\left[\mathrm{Ca}_{2} \mathrm{PO}_{3}^{+}\right],\left[\mathrm{Ca}_{2} \mathrm{PO}_{4}^{+}\right]$, and $\left[\mathrm{Ca}_{3} \mathrm{PO}_{5}^{+}\right]$, respectively, were detected. It was previously reported that these signatures indicate inorganic HAP (36), suggesting nodules also contain this calcium phosphate compound. Molecular mapping of $\left[\mathrm{Ca}^{+}\right],\left[\mathrm{CaPO}_{2}^{+}\right]$, and the sum of all detected $\mathrm{CaP}$ signatures confirmed the presence of calcium phosphate within nodules (Fig. S6). 
Calcific lesions stained with the apatite-specific bio-imaging agent OsteoSense 680EX were shown using confocal fluorescence microscopy (Table S2). Nodules were heterogeneously stained, with crusts staining intensely (Fig. 4 N, arrowhead); as previously reported, $(9,10)$ some spherules appeared to have a hollow core of apatite (Fig. 4 0) and also plaques stained with OsteoSense 680EX (Fig. 4 P). These results suggest that nodules, spherules and plaques were all composed of apatite.

The detection of secondary ions associated with $\mathrm{HAP}$ such as $\left[\mathrm{Ca}^{+}\right],[\mathrm{CaO}+],\left[\mathrm{CaPO}_{2}^{+}\right]$, $\left[\mathrm{Ca}_{2} \mathrm{PO}_{3}{ }^{+}\right],\left[\mathrm{Ca}_{2} \mathrm{PO}_{4}^{+}\right]$, and $\left[\mathrm{Ca}_{3} \mathrm{PO}_{5}^{+}\right](36)$, as well as positive OsteoSense 680EX staining suggested HAP could be the major constituent of nodules. To explore the phases of calcium phosphate present in nodules, spherules and plaques, we employed transmission electron microscopy (TEM) - selected area electron diffraction (SAED) on samples sectioned by a focused ion beam (FIB).

Each deposit was first characterized by TEM (Fig. 5 A-I). As observed by light microscopy, nodules had numerous lobes, $\sim 1-20 \mu \mathrm{m}$ in diameter (Fig. 5 A, D, each with a distinct electrondense outer crust and a less electron-dense inner core (Fig. 5 A, D). Like nodules, spherules were also electron-dense with an inner core and a distinct outer shell (Fig. 5 B, E). In contrast to lobular or spherical deposition in nodules and spherules, respectively, calcium phosphate deposition in BrM plaques appear as disordered and crosshatched crystal needles (Fig. 5 C, F).

Subsequently, the calcium phosphate phases forming nodules, spherules and BrM plaques were determined using SAED (Fig. 5 G, H, I). SAED produces diffractions rings that represent the distance (d-spacing or inter-planar) between planes of atoms within a crystal lattice. These can be used to identify the mineral phase of a sample (37). Diffraction patterns obtained from nodules indicated a polycrystalline material composed of numerous unorganized crystals (Fig. 5 G). Diffraction rings including (002), (300), (211) and (006) (37) confirmed that nodules were 
composed of HAP (Table S3). Spherules diffracted as a single crystal producing a spot pattern correlating to (010) zone axes of Whitlockite (Fig. 5 H). In contrast, BrM plaques produced diffuse rings indicating the presence of an amorphous material of very low crystallinity (Fig. 5 I). A diffuse ring encompassing multiple diffraction rings characteristic of apatite was detected (Fig. $5 \mathrm{I})$. 


\section{DISCUSSION}

Already a powerful tool to diagnose retinal disease, monitor progression, and provide end-points for clinical trials (38), multimodal OCT-based clinical imaging can help define molecular pathogenesis if linked to the composition of visualized structures. Herein we replicate and extend previous findings that HIRDs associate with progression to advanced AMD, by applying the same imaging criteria to an independent cohort. Further, we use histology, multimodal clinical imaging, and high resolution molecular imaging to show that HIRDs are sprawling polycrystalline HAP nodules, distinctly different from the restricted sized spherules in drusen .

We propose a novel 4-stage pathway for druse progression to HIRD by longitudinal multimodal clinical imaging (Fig. S7). Variation A has less, and Variation B has more, overlying BLamD, and similar trends were seen in both (Fig. S8; Table S1). Stage 1: druse under intact RPE and a thin layer of BLamD. Druse contents are homogenously and moderately hyperreflective, without evidence of a hyporeflective core. HAP spherules (10) are undetectable due to shadowing by the RPE (20), the continuity of which is confirmed by FAF. Stage 2 A: a hyporeflective core representing a nodule under intact RPE and surrounded by hyperreflective dots. Within overlying retina, hyperreflective foci (migrating RPE) (39) are visible. Stage 3 A: focal loss of RPE, visible on OCT as disruption and thinning of the hyperreflective RPE-basal lamina band, gradually exposing the druse interior, which is reduced in volume. RPE loss is indicated by central hypoautofluorescence within a hyperautofluorescent border. Stage 4 A: complete loss of RPE overlying the nodule-filled druse, signified by absent FAF signal and a thin hyperreflective border of persistent BLamD. Relative to variation A, variation B exhibited less refractility on CFP, more hyperautofluorescence, and less hyper-reflectivity on NIR (Fig. S7). Most HIRD lesions were observed at Stages 2 and 3 (Figs. S1, S8). 
We further propose (Fig. S7) that in the presence of high overall extracellular calcium concentration, higher extracellular magnesium concentration and an acidic $\mathrm{pH}$ might promote spherule formation while a lower magnesium concentration and neutral $\mathrm{pH}$ might promote nodule formation, as elaborated below. We suggest that the sub-RPE-BL space transforms to a nodule-promoting environment by decreased release of $\mathrm{Mg}^{+2}$ as RPE cells die or migrate anteriorly atop drusen (40), therefore suggesting that HIRDs might be indicators of RPE in its agonal state. This interpretation is supported by focal HIRD-associated hypoautofluorescence (Fig. S7). Thus, progression risk might be conferred not so much by HIRD themselves but by what they signify about RPE health.

Refractile drusen, appearing on ophthalmoscopy and CFP as glistening with reflective dots, were called "calcified" based on appearance and early studies using the von Kossa stain for phosphates $(34,41-43)$. These highly reflective features are associated with HIRD on OCT and higher rates of incidence of progression to advanced AMD in previous studies from our group, either alone or together with 3 other indicators $(19,21)$. OCT-reflective drusen substructures including ones resembling stage 4 HIRD (Fig. S7) were associated with rapid progression to GA but not to neovascular AMD in a large cohort of patients with intermediate AMD, perhaps because only 14 individuals had this phenotype (32). Our study expands this literature by showing in a large patient sample that the hyporeflective cores of drusen confer risk for advancement to both end-stages, and demonstrating that they are HAP nodules. By appearance and composition, nodules are not simply aggregations of recently described HAP spherules (10). Unlike spherules, which are small, refractile on CFP, and reflective on OCT, nodules are large, refractile on CFP, and non-reflective on OCT, a difference possibly due to the nodules' rough surface and size. Nodules are hyporeflective like other calcified structures (50 $\mu \mathrm{m}-1 \mathrm{~mm})$ in the posterior eye $(44,45)$. We suggest that HIRD be called 'calcific nodules' going forward instead of an alternative term 'hyperreflective pyramidal structures'(22) or 
$\mathrm{C}$ (onical) drusen (32). Our proposed term describes both the composition and structure of the hyporeflective core, which our data support as an indicator of AMD progression (46). Further, HIRD can now be differentiated from lines with an intense, mirror-like hyperreflectivity in or near BrM that also strongly associate with atrophy $(23,24,47-49)$ and may correlate to single or sparse cholesterol crystals $(50,51)$. These crystals signify replacement of oily drusen with fluid or fibrotic contents that are sufficiently hydrated to support supersaturation and precipitation within this compartment. $(50,51)$

We observed distinct variations in calcium phosphate phases within specific deposits. Using x-ray diffraction, we previously reported HAP-enriched spherules in drusen (10) and in deposits formed by RPE cells in culture (29). Combining TEM, EDX and SAED, we identified highly crystalline whitlockite spherules, polycrystalline HAP nodules, and poorly crystalline apatite plaques. Whitlockite, a magnesium-substituted calcium phosphate previously associated with several diseases (52-54) is herein reported in human eyes. Preferential whitlockite formation over HAP has been linked to acidic $\mathrm{pH}$ and increased magnesium $(\mathrm{Mg})$ to calcium (Ca) ratio $(55,56)$, among other mechanisms. In the kidney, the frequency of apatite and whitlockite phases is unaffected by systemic $\mathrm{Mg}$ cation $\left(\mathrm{Mg}^{+2}\right)$ load (53), suggesting that local $\mathrm{Mg}^{+2}$ concentration determines which calcium phosphate phase forms. Therefore, appropriate $\mathrm{Mg}^{+2}$ in the sub-RPE-BL space might promote formation of whitlockite spherules (Fig. S7). Mg $^{+2}$ can substitute a small proportion of $\mathrm{Ca}^{+2}$ in the HAP lattice causing inhibition of HAP crystal growth $(54,57)$, possibly explaining the restricted size of spherules. In contrast, the absence of $\mathrm{Mg}^{+2}$ in nodules may signify that low local $\mathrm{Mg}^{+2}$ concentrations facilitate continued crystal growth and thus greater size. Finally, despite detectable $\mathrm{Mg}^{+2}$ in plaques, the low crystallinity and association of plaque calcification with $\operatorname{BrM}$ collagen and elastin $(26,58)$ did not allow calcium phosphate phases to be identified. After examining numerous sub-RPE deposits of all sizes in our ongoing studies, we are yet to see one without spherules. Thus, we suggest that spherule 
formation is a natural endpoint for calcium phosphate formation, $\mathrm{Mg}^{+2}$ in the sub-RPE-BL space keeps crystal growth at bay, whereas reduced $\mathrm{Mg}^{+2}$ concentrations lead to continuous nodule growth (Fig. S7). Our results show that spherules and nodules coexist, but nodules seem to be visible on OCT at the later stages of AMD progression compared to spherules. BrM plaques by their focal spatial confinement can be contrasted with widespread BrM calcification in the inherited disorder pseudoxanthoma elasticum (OMIM 264800), (59) suggesting again local pathogenic regulation of mineralization within the druse. In pseudoxanthoma elasticum, BrM is reflective with a rough surface on OCT (60), however, whether the smaller plaques in AMD will be similarly visible is not yet known.

What extracellular factors potentially modulate apatite formation in AMD? Organic molecules like functional groups of amino acids, as part of proteins in solution $(61,62)$, can inhibit HAP formation. However, when immobilized or entrapped on surfaces $(62,63)$, like in aged BrM, proteins can promote mineral deposition. Similarly, lipids can also nucleate mineral deposition, including both HAP and whitlockite (64-66). Soft drusen, in which nodules preferentially form, are rich in lipids thought to be derived from RPE-secreted lipoprotein particles in an outer retinal lipid recycling program $(8,12,13,67,68)$. Direct support for lipidassociated mineralization includes the identification of a cholesterol core within spherules (10) as well as detection of phosphatidylcholine within sub-RPE deposits produced by confluent and functional RPE cells in culture (29). Whilst the mechanism(s) and full range of contributory proteins and lipids are yet to be identified, our data support a model of organic molecules nucleating inorganic mineral deposits. Once seeded, mineralized surfaces could become sites for further protein deposition $(10,29)$. Independent of the seeding mechanisms, $\mathrm{Ca}^{+2}$ and $\mathrm{P}$ supersaturation is essential to initiate mineralization. In tissues, $\mathrm{Ca}^{+2}$ availability is tightly regulated with high affinity binding proteins (69) and extracellular phosphate concentration is low $(70,71)$. Nevertheless, we observed HAP deposition by RPE cells cultured under standard 
conditions, suggesting that seemingly healthy RPE cells establish an environment conducive to mineral nucleation and growth (29). How HAP deposition occurs in vitro and whether whitlockite formation can be promoted by modulating culture medium $\mathrm{pH}$ and $\mathrm{Mg}$ concentration should now be investigated.

Under "normal" circumstances neither $\mathrm{Mg}^{+2}$ nor $\mathrm{Ca}^{+2}$ are available for mineralization in the extracellular space $(72,73)$. We speculate that with aging, especially pathological aging, this availability changes. In the presence of sufficient extracellular $\mathrm{Mg}^{+2}$ and high concentration of $\mathrm{Ca}^{+2}$, spherules may be formed. At low extracellular $\mathrm{Mg}^{+2}$ and high $\mathrm{Ca}^{+2}$, the $\mathrm{Mg}$ control of mineral growth would be lost so that nodules start proliferating. This proliferation is associated with progression to $\mathrm{AMD}$, therefore, we propose that this condition might associated with increasingly non-functional RPE overlying drusen, whereas the presence of functional RPE overlying drusen could help whitlockite spherule formation. A review of data obtained from our RPE culture experiments failed to confirm the presence of $\mathrm{Mg}^{+2}$ within the in vitro mineralized deposits, suggesting that even these apparently functional cells are stressed and in $\mathrm{Ca}^{+2}-\mathrm{Mg}^{+2}$ imbalance (29).

We also considered how extracellular $\mathrm{Ca}^{+2}-\mathrm{Mg}^{+2}$ imbalance may be influenced by intracellular mechanisms, focusing attention on mitochondria. Mitochondria have stores high concentration of calcium with ultrastructurally visible microparticles of calcium phosphate and these had been suggested to play a role in extracellular HAP deposition in both health (for example, in bone) and in tissue injury $(74,75)$. In disease, calcium can be released from the mitochondria through opening of mitochondrial permeability transition pores leading to swelling, rupture, and release of mitochondrial contents into the cytosol then into the extracellular space (76). In eyes with AMD reduced DICER1 concentration results in accumulation of Alu-RNA, which is in turn is associated with cytosolic release of mitochondrial DNA and presumably $\mathrm{Ca}^{+2}$ (77). Mitochondrial damage and loss in the human RPE is associated with age (78), especially 
in the macula, especially in AMD severity $(77,79-81)$. Therefore, mitochondrial calcium stores released by failing RPE cells could exit to the extracellular sub-RPE-BL space and tip the $\mathrm{Ca}^{+2}$ $\mathrm{Mg}^{+2}$ balance.

Pathways regulating sub-RPE Ca and Mg concentrations are unknown, suggesting aspects of cellular physiology needing exploration. Ca signaling by the RPE is well-studied and essential to the activity of apical and basolateral potassium and chloride channels that collectively regulate the ionic environment of photoreceptors, photoreceptor-RPE adherence, and net fluid efflux from retina to choroid (82). Ca signaling is also important for health of lysosomes (83) needed for RPE processing of ingested photoreceptor tips and diet-delivered lipids. Mg homeostasis is less well studied, although in its ionic form, $\mathrm{Mg}^{+2}$ is required by many kinases, including those involved in maintaining apically located, inward-rectifying potassium currents in RPE $(84,85)$. Further, developmental Mg deficiency causes focal RPE degeneration and excess $\mathrm{Ca} / \mathrm{Mg}$ ratio in retina (86).

Strengths of this study include multidisciplinary converging evidence showing 3 distinct refractile structures associated with GA: 1) small highly crystalline whitlockite spherules that account for hyperreflective dots on OCT and NIR, 2) large nodules containing polycrystalline calcium phosphate and appearing hyporeflective on OCT and iso-reflective on NIR, and 3) amorphous crystalline plaques in BrM. Common features amongst these are $\mathrm{Ca}$ - and $\mathrm{P}$ containing mineralization signifying molecular processes that can now be informed by research relevant to other conditions. Limitations include the small number of samples available for mineralomic characterization and the current lack of an imaging correlate for $\mathrm{BrM}$ plaques. Future directions include extending the clinical observations to other patient cohorts, identification of imaging signatures prior to calcification, and exploring whether local and systemic $\mathrm{Ca}^{+2}$ and $\mathrm{Mg}^{+2}$ regulation are targets for $\mathrm{AMD}$ treatment and prevention, as current clinical data are mixed (87-89). Nevertheless, we conclude that extracellular mineralization in 
the form of nodules indicates risk for progression to late AMD, because it reveals the agonal state of the overlying RPE. Elucidating the timeline of RPE demise by imaging mineralization may help direct new therapeutic approaches to disease stages earlier than geographic atrophy. 


\section{Materials and Methods}

\section{Study design}

Both clinical cohorts were approved by their respective Institutional Review Boards and complied with the Health Insurance Portability and Accountability Act of 1996 and the Declaration of Helsinki. The use of human tissue samples was approved by institutional review boards at the University of Alabama at Birmingham and University College London.

Cohort 1 of AMD patients for multimodal imaging of defined deposits: To establish stages of deposit progression, a cohort of consecutive patients with heterogeneous internal reflectivity in drusen (HIRD) on OCT imaging, seen by a single retinal specialist (KBF) at a tertiary private retinal practice, was retrospectively reviewed. Inclusion criteria were eyes with GA with at least one HIRD seen on OCT with at least a 3 year follow up with OCT volume scans taken on at least 10 consecutive visits. The exclusion criteria included presence of any neovascular AMD during the course of follow up, other retinal vascular or degenerative diseases, and eyes with significant media opacity that affected imaging quality.

Cohort 2 of eyes with intermediate AMD for longitudinal observation To establish the prevalence and progression risk of HIRD, a cohort of a total of 840 eyes of 420 consecutive patients with AMD seen by a single retinal specialist (SRS) between 2010 and 2014 in a tertiary care academic retinal practice in Los Angeles was retrospectively reviewed. From this dataset, we selected all subjects who had at least one eye with evidence of intermediate AMD, defined according to the Beckman classification (90), no other posterior segment ocular disease, dense OCT volume scans (Cirrus OCT with 128 B-scans over a $6 \times 6 \mathrm{~mm}$ region centered on the fovea), and at least 12 months of follow-up data including OCT. Dense volume scans with this spacing of just under $50 \mu \mathrm{m}$ between scans was required in order avoid missing the center of large drusenoid lesions between the B-scans, which was critical for reliable assessment of druse core reflectivity characteristics. Twelve months of follow-up data was 
required. When both eyes of one subject met these inclusion criteria, one eye was randomly selected for analysis. A total of 138 eyes from 138 subjects met these criteria. OCT scans at baseline were reviewed by certified OCT graders at the Doheny Image Reading Center to assess for presence of hyporeflective cores within the drusen. Graders were masked as to other clinical data regarding the patients. Clinical charts and follow-up imaging data were evaluated over the next 12 months to ascertain the frequency of progression GA or CNV.

Imaging-histology correlations in donor eyes with AMD

Spectral domain OCT imaging of human donor eyes followed by high-resolution histology provided a link between clinical imaging and microanalysis of selected drusen. Three separate series of eyes were reviewed for suitable specimens, all drawn from a repository of $\geq 900$ pairs of donor eyes accessioned from the Alabama Eye Bank for research purposes 1995-2012. 1) Eyes for OCT imaging and histology (Figs. 2-3) were used for the creation of the Project MACULA online AMD histology resource (http://projectmacula), 139 maculas, median death-topreservation time was 3.62 hours (range, $0.67-12.15$ hours). These were subject to ex vivo multimodal imaging including OCT, NIR, and $488 \mathrm{~nm}$ and $787 \mathrm{~nm}$ FAF, using a custom tissue holder and a Spectralis HRA+OCT (Heidelberg Engineering), in addition to digital color photography(50). Specimens were post-fixed in osmium tannic acid paraphenylenediamine to preserve extracellular lipid, embedded in epoxy resin, sectioned at $0.8 \mu \mathrm{m}$, and stained with toluidine blue (34). 2) For advanced mineralomics, one eye with distinctive glistening drusen from the ALARMGS series of eyes $(n=30)(34)$ was used and shown in Fig. S2. All eyes underwent ex vivo color imaging using epi- and trans-scleral illumination, followed by postfixation in osmium only, en bloc staining with uranyl acetate, and epoxy embedding. 3) For advanced mineralomics in Figs. 4 and 5, 4 blocks of 4 eyes were taken from a series of 9 eyes of 7 donors with large macular drusen imaged by ex vivo color reflectance photography, micro- 
dissected, post-fixed by the osmium tannic acid paraphenylenediamine method, and histologically confirmed as having spherules and/or nodules (35).

In addition to these clinically undocumented eyes, one eye of a patient with in vivo clinical OCT was used for direct clinicopathologic correlation (Fig. 2 A-D). An 86-year-old white woman had geographic atrophy in the left eye. Four months after her last clinic visit and 7:30 hr after death, eyes were recovered and preserved as described (91). Histology proceeded as described above for series 1 .

\section{Sample source for mineralomic studies}

Human cadaveric eyes with sub-RPE deposits and Bruch's membrane plaques were obtained from the University College London Institute of Ophthalmology and Moorfield's Eye Hospital Tissue Repository. Cadaveric eyes were enucleated 12-24 hours after death and preserved in $1 \%$ glutaraldehyde with $4 \%$ paraformaldehyde. Spherules, nodules, and plaques were identified in these specimens by comparison of morphology to specimens with clinical and/ or ex vivo imaging documentation of AMD with large macular drusen, as described above.

\section{Statistical analysis}

For cohort 1, statistical analysis was performed using an online statistical calculator (http://vassarstats.net/) and a $p<0.05$ was considered significant. To determine if there was a significant difference in appearance of the 2 variant stages, the Fisher exact test was used (Figure S8, Dataset S1). For cohort 2, binary Logistic regression was performed to determine the influence of HIRD on the progression to either GA or CNV using SPSS Statistics for Windows (Released 2016. Version 24.0.). Due to the lack of multiples of clinically highly characterized samples, statistical analysis was not applied to the mineralomic studies but representative samples were used and presented throughout (see Table S2). 
Supplementary Material:

Figure S1: Appearance of heterogeneous internal reflectivity in drusen (HIRD) as seen on multimodal imaging during progression.

Figure S2: Refractile drusen with nodules and RPE atrophy in the index case for microanalysis.

Figure S3. Scanning electron microscopy of isolated nodules.

Figure S4. Density dependent color - scanning electron microscopy of calcific lesions.

Figure S5. Synchrotron microfocus x-ray fluorescence confirms the presence of $\mathrm{Ca}$ in large nodules.

Figure S6. Time of flight-secondary ion mass spectrometry confirms the presence of hydroxyapatite within nodules.

Figure S7: Proposed progression stages of calcified structures in AMD.

Figure S8: Two variants of heterogeneous internal reflectivity in drusen.

Table S1: Composition and appearance of calcified structures in eyes with geographic atrophy as revealed by multi-modal clinical and molecular imaging.

Table S2: Table of Sample Sources.

Table S3: D spacings and I/Imax (\%) of candidate calcium phosphate compounds.

Dataset S1: Primary data from cohort 1.

Dataset S2: Primary data from cohort 2.

MOVIE S1: Progression of nodules, spherules and Bruch's membranes plaques. 
Calcification in age-related macular degeneration

\section{Supplementary Methods:}

Multimodal imaging protocol and analysis

Scanning electron microscopy and energy dispersive $x$-ray spectroscopy

Secondary ion mass spectrometry of calcific lesions

Synchrotron microfocus $x$-ray fluorescence

Hydroxyapatite specific fluorescent labelling of calcific lesions

Focused ion beam milling of cadaveric tissues

Transmission electron microscopy - selected area electron diffraction 


\section{REFERENCES}

1. W. L. Wong, X. Su, X. Li, C. M. Cheung, R. Klein, C. Y. Cheng, T. Y. Wong, Global prevalence of age-related macular degeneration and disease burden projection for 2020 and 2040: a systematic review and meta-analysis. Lancet Glob Health 2, e106-116 (2014).

2. M. G. Maguire, D. F. Martin, G. S. Ying, G. J. Jaffe, E. Daniel, J. E. Grunwald, C. A. Toth, F. L. Ferris, 3rd, S. L. Fine, Five-year outcomes with anti-vascular endothelial growth factor treatment of neovascular age-related macular degeneration: the Comparison of Age-Related Macular Degeneration Treatments Trials. Ophthalmology 123, 1751-1761 (2016).

3. U. Chakravarthy, C. C. Bailey, R. L. Johnston, M. McKibbin, R. S. Khan, S. Mahmood, L. Downey, N. Dhingra, C. Brand, C. J. Brittain, J. R. Willis, S. Rabhi, A. Muthutantri, R. A. Cantrell, Characterizing disease burden and progression of geographic atrophy secondary to age-related macular degeneration. Ophthalmology, (2018).

4. T. G. Farkas, V. Sylvester, D. Archer, M. Altona, The histochemistry of drusen. American Journal of Ophthalmology 71, 1206-1215 (1971).

5. D. Pauleikhoff, S. Zuels, G. S. Sheraidah, J. Marshall, A. Wessing, A. C. Bird, Correlation between biochemical composition and fluorescein binding of deposits in Bruch's membrane. Ophthalmol. 99, 1548-1553 (1992).

6. C. A. Curcio, C. L. Millican, T. Bailey, H. S. Kruth, Accumulation of cholesterol with age in human Bruch's membrane. Invest. Ophthalmol. Vis. Sci. 42, 265-274 (2001).

7. R. Haimovici, D. L. Gantz, S. Rumelt, T. F. Freddo, D. M. Small, The lipid composition of drusen, Bruch's membrane, and sclera by hot stage polarizing microscopy. Invest. Ophthalmol. Vis. Sci. 42, 1592-1599 (2001).

8. C. A. Curcio, J. B. Presley, G. Malek, N. E. Medeiros, D. V. Avery, H. S. Kruth, Esterified and unesterified cholesterol in drusen and basal deposits of eyes with age-related maculopathy. Exp Eye Res 81, 731-741 (2005).

9. J. M. Flinn, P. Kakalec, R. Tappero, B. Jones, I. Lengyel, Correlations in distribution and concentration of calcium, copper and iron with zinc in isolated extracellular deposits associated with age-related macular degeneration. Metallomics 6, 1223 - 1228 (2014).

10. R. B. Thompson, V. Reffatto, J. G. Bundy, E. Kortvely, J. M. Flinn, A. Lanzirotti, E. A. Jones, D. S. McPhail, S. Fearn, K. Boldt, M. Ueffing, S. G. Ratu, L. Pauleikhoff, A. C. Bird, I. Lengyel, Identification of hydroxyapatite spherules provides new insight into subretinal pigment epithelial deposit formation in the aging eye. Proc Natl Acad Sci U S A 112, 1565-1570 (2015).

11. J. W. Crabb, M. Miyagi, X. Gu, K. Shadrach, K. A. West, H. Sakaguchi, M. Kamei, A. Hasan, L. Yan, M. E. Rayborn, R. G. Salomon, J. G. Hollyfield, Drusen proteome analysis: an approach to the etiology of age-related macular degeneration. Proc Natl Acad Sci U S A 99, 14682-14687. (2002).

12. G. Malek, C.-M. Li, C. Guidry, N. E. Medeiros, C. A. Curcio, Apolipoprotein B in cholesterolcontaining drusen and basal deposits in eyes with age-related maculopathy. Am. J. Pathol. 162, 413-425 (2003).

13. L. Wang, M. E. Clark, D. K. Crossman, K. Kojima, J. D. Messinger, J. A. Mobley, C. A. Curcio, Abundant lipid and protein components of drusen. PLOS ONE 5, e10329 (2010).

14. A. L. Fett, M. M. Hermann, P. S. Muether, B. Kirchhof, S. Fauser, Immunohistochemical localization of complement regulatory proteins in the human retina. Histology and histopathology 27, 357-364 (2012).

15. J. P. Sarks, S. H. Sarks, M. C. Killingsworth, Evolution of soft drusen in age-related macular degeneration. Eye 8, 269-283 (1994). 
16. C. A. Curcio, Soft drusen in age-related macular degeneration: biology and targeting, via the Oil Spill Strategy. Invest Ophthalmol Vis Sci 9/4/18 accepted, (2018).

17. F. G. Holz, S. Sadda, G. Staurenghi, M. Lindner, A. C. Bird, B. A. Blodi, B. Bottoni, U. Chakravarthy, E. Chew, K. Csaky, C. A. Curcio, R. Danis, K. B. Freund, J. Grunwald, R. Guymer, C. Hoyng, G. J. Jaffe, S. Liakopoulos, J. Monés, A. Oishi, D. Pauleikhoff, P. J. Rosenfeld, D. Sarraf, R. F. Spaide, R. Tadayoni, A. Tufail, S. Wolf, S. Schmitz-Valckenberg, Imaging protocols for clinical studies in agerelated macular degeneration - recommendations from Classification of Atrophy (CAM) Consensus Meeting. Ophthalmology 124, 464-478 (2017).

18. S. T. Garrity, D. Sarraf, K. B. Freund, S. R. Sadda, Multimodal imaging of nonneovascular agerelated macular degeneration. Invest Ophthalmol Vis Sci 59, AMD48-AMD64 (2018).

19. J. Lei, S. Balasubramanian, N. S. Abdelfattah, M. Nittala, S. R. Sadda, Proposal of a simple optical coherence tomography-based scoring system for progression of age related macular degeneration. Graefes Arch Clin Exp Ophthalmol 255, 1551-1558 (2017).

20. M. Suzuki, C. A. Curcio, R. F. Mullins, R. F. Spaide, Refractile drusen: clinical imaging and candidate histology. Retina 35, 859-865 (2015).

21. Y. Ouyang, F. M. Heussen, A. Hariri, P. A. Keane, S. R. Sadda, Optical coherence tomographybased observation of the natural history of drusenoid lesion in eyes with dry age-related macular degeneration. Ophthalmology 120, 2656-2665 (2013).

22. C. Bonnet, G. Querques, J. Zerbib, H. Oubraham, R. B. Garavito, N. Puche, E. H. Souied, Hyperreflective pyramidal structures on optical coherence tomography in geographic atrophy areas. Retina 34, 1524-1530 (2014).

23. M. Fleckenstein, P. Charbel Issa, H. M. Helb, S. Schmitz-Valckenberg, R. P. Finger, H. P. Scholl, K. U. Loeffler, F. G. Holz, High-resolution spectral domain-OCT imaging in geographic atrophy associated with age-related macular degeneration. Invest Ophthalmol Vis Sci 49, 4137-4144 (2008).

24. K. Moussa, J. Y. Lee, S. S. Stinnett, G. J. Jaffe, Spectral domain optical coherence tomographydetermined morphologic predictors of age-related macular degeneration-associated geographic atrophy progression. Retina 33, 1590-1599 (2013).

25. R. J. Ulshafer, C. B. Allen, B. Nicolaissen, Jr., M. L. Rubin, Scanning electron microscopy of human drusen. Invest Ophthalmol Vis Sci 28, 683-689. (1987).

26. T. L. van der Schaft, W. C. de Bruijn, C. M. Mooy, D. A. M. Ketelaars, P. T. V. M. de Jong, Element analysis of the early stages of age-related macular degeneration. Archives of Ophthalmology 110, 389-394 (1992).

27. S. D. Vogt, C. A. Curcio, L. Wang, C.-M. Li, G. McGwin, Jr, N. E. Medeiros, N. J. Philp, J. A. Kimble, R. W. Read, Retinal pigment epithelial expression of complement regulator CD46 is altered early in the course of geographic atrophy. Exp Eye Res 93, 413-423 (2011).

28. W. L. Davis, R. G. Jones, H. K. Hagler, An electron microscopic histochemical and analytical X-ray microprobe study of calcification in Bruch's membrane from human eyes. $J$ Histochem Cytochem 29, 601-608. (1981).

29. M. G. Pilgrim, I. Lengyel, A. Lanzirotti, M. Newville, S. Fearn, E. Emri, J. C. Knowles, J. D. Messinger, R. W. Read, C. Guidry, C. A. Curcio, Sub-retinal pigment epithelial deposition of drusen components including hydroxyapatite in a primary cell culture model. Invest Ophthalmol Vis Sci 58, 708-719 (2017).

30. P. Fratzl, R. Weinkamer, Nature's hierarchical materials. Prog Material Sci 52, 1263-1334 (2007).

31. S. Bertazzo, E. Gentleman, K. L. Cloyd, A. H. Chester, M. H. Yacoub, M. M. Stevens, Nanoanalytical electron microscopy reveals fundamental insights into human cardiovascular tissue calcification. Nat Mater 12, 576-583 (2013). 
32. M. Veerappan, A. M. El-Hage-Sleiman, V. Tai, S. J. Chiu, K. P. Winter, S. S. Stinnett, T. S. Hwang, G. B. Hubbard, 3rd, M. Michelson, R. Gunther, W. T. Wong, E. Y. Chew, C. A. Toth, Age-related Eye Disease Study 2 Ancillary Spectral Domain Optical Coherence Tomography Study Group, Optical coherence tomography reflective drusen substructures predict progression to geographic atrophy in age-related macular degeneration. Ophthalmology 123, 2554-2570 (2016).

33. J. P. Sarks, S. H. Sarks, M. C. Killingsworth, Evolution of geographic atrophy of the retinal pigment epithelium. Eye 2, 552-577 (1988).

34. C. A. Curcio, N. E. Medeiros, C. L. Millican, The Alabama Age-related Macular Degeneration Grading System for donor eyes. Invest. Ophthalmol. Vis. Sci. 39, 1085-1096 (1998).

35. M. Rudolf, M. E. Clark, M. Chimento, C.-M. Li, N. E. Medeiros, C. A. Curcio, Prevalence and morphology of druse types in the macula and periphery of eyes with age-related maculopathy. Invest Ophthalmol Vis Sci 49, 1200-1209 (2008).

36. P. Malmberg, H. Nygren, Methods for the analysis of the composition of bone tissue, with a focus on imaging mass spectrometry (TOF-SIMS). Proteomics 8, 3755-3762 (2008).

37. B. D. Cullity, S. R. Stock, Elements of X-ray Diffraction. (Pearson, 2001).

38. P. J. Rosenfeld, Optical coherence tomography and the development of antiangiogenic therapies in neovascular age-related macular degeneration. Invest Ophthalmol Vis Sci 57, OCT14-26 (2016).

39. C. Balaratnasingam, J. D. Messinger, K. R. Sloan, L. A. Yannuzzi, K. B. Freund, C. A. Curcio, Histologic and optical coherence tomographic correlations in drusenoid pigment epithelium detachment in age-related macular degeneration. Ophthalmology 124, 644- 656 (2017).

40. C. A. Curcio, E. C. Zanzottera, T. Ach, C. Balaratnasingam, K. B. Freund, Activated retinal pigment epithelium, an optical coherence tomography biomarker for progression in age-related macular degeneration. Invest Ophthalmol Vis Sci 58, BIO211-BIO226 (2017).

41. J. D. M. Gass, Pathogenesis of disciform detachment of the neuroepithelium. III. Senile disciform macular degeneration. Am. J. Ophthalmol. 63, 617-644 (1967).

42. W. R. Green, S. N. Key, 3rd, Senile macular degeneration: a histopathologic study. Trans Am Ophthalmol Soc 75, 180-254 (1977).

43. N. M. Bressler, J. C. Silva, S. B. Bressler, S. L. Fine, W. R. Green, Clinicopathological correlation of drusen and retinal pigment epithelial abnormalities in age-related macular degeneration. Retina 14, 130-142 (1994).

44. F. Pichi, D. Massaro, M. Serafino, P. Carrai, G. P. Giuliari, C. L. Shields, C. Veronese, A. P. Ciardella, P. Nucci, Retinal astrocytic hamartoma: optical coherence tomography classification and correlation with tuberous sclerosis complex. Retina 36, 1199-1208 (2016).

45. T. Sato, S. Mrejen, R. F. Spaide, Multimodal imaging of optic disc drusen. Am J Ophthalmol 156, 275-282 e271 (2013).

46. Y. Ouyang, F. M. Heussen, P. A. Keane, R. K. Pappuru, S. R. Sadda, A. C. Walsh, Juxtapapillary pigment epithelium detachment observed in asymptomatic participants using optical coherence tomography. Invest Ophthalmol Vis Sci 54, 1144-1149 (2013).

47. G. Querques, A. Georges, N. Ben Moussa, M. Sterkers, E. H. Souied, Appearance of regressing drusen on optical coherence tomography in age-related macular degeneration. Ophthalmology 121, 173-179 (2014).

48. M. J. Heiferman, A. A. Fawzi, Discordance between blue-light autofluorescence and nearinfrared autofluorescence in age-related macular degeneration. Retina 36 Suppl 1, S137-S146 (2016). 
49. A. Oishi, S. Thiele, J. Nadal, M. Oishi, M. Fleckenstein, M. Schmid, F. G. Holz, S. SchmitzValckenberg, Prevalence, natural course, and prognostic role of refractile drusen in age-related macular degeneration. Invest Ophthalmol Vis Sci 58, 2198-2206 (2017).

50. C. Pang, J. D. Messinger, E. C. Zanzottera, K. B. Freund, C. A. Curcio, The Onion Sign in neovascular age-related macular degeneration represents cholesterol crystals. Ophthalmology 122, 2316-2326 (2015).

51. M. Li, R. Dolz-Marco, J. D. Messinger, K. R. Sloan, D. Ferrara, C. A. Curcio, K. B. Freund, Clinicopathologic correlation of aneurysmal type 1 neovascularization in age-related macular degeneration. Ophthalmology Retina $\mathbf{9 / 8 / 1 8}$ online, (2018).

52. S. C. Verberckmoes, V. Persy, G. J. Behets, E. Neven, A. Hufkens, H. Zebger-Gong, D. Muller, D. Haffner, U. Querfeld, S. Bohic, M. E. De Broe, P. C. D'Haese, Uremia-related vascular calcification: more than apatite deposition. Kidney Int 71, 298-303 (2007).

53. D. C. Fischer, G. J. Behets, O. W. Hakenberg, M. Voigt, B. A. Vervaet, S. Robijn, G. Kundt, W. Schareck, P. C. D'Haese, D. Haffner, Arterial microcalcification in atherosclerotic patients with and without chronic kidney disease: a comparative high-resolution scanning $X$-ray diffraction analysis. Calcif Tissue Int 90, 465-472 (2012).

54. R. Lagier, C. A. Baud, Magnesium whitlockite, a calcium phosphate crystal of special interest in pathology. Pathol Res Pract 199, 329-335 (2003).

55. T. Kani, M. Kani, Y. Moriwaki, Y. Doi, Microbeam x-ray diffraction analysis of dental calculus. J Dent Res 62, 92-95 (1983).

56. A. C. Tas, Synthesis of biomimetic Ca-hydroxyapatite powders at 37 degrees $\mathrm{C}$ in synthetic body fluids. Biomaterials 21, 1429-1438 (2000).

57. R. Villa-Bellosta, Impact of magnesium:calcium ratio on calcification of the aortic wall. PLoS One 12, e0178872 (2017).

58. M. J. Hogan, J. A. Alvarado, J. E. Weddell, Histology of the Human Eye. An Atlas and Textbook., (W. B. Saunders, Philadelphia, 1971), pp. 328-363.

59. O. A. Jensen, Bruch's membrane in pseudoxanthoma elasticum. Histochemical, ultrastructural, and $\mathrm{x}$-ray microanalytical study of the membrane and angioid streak areas. Albrecht Von Graefes Arch Klin Exp Ophthalmol 203, 311-320 (1977).

60. M. Gliem, R. Fimmers, P. L. Muller, C. K. Brinkmann, R. P. Finger, D. Hendig, F. G. Holz, P. C. Issa, Choroidal changes associated with Bruch membrane pathology in pseudoxanthoma elasticum. Am J Ophthalmol, (2014).

61. I. Hirata, M. Akamatsu, E. Fujii, S. Poolthong, M. Okazaki, Chemical analyses of hydroxyapatite formation on SAM surfaces modified with $\mathrm{COOH}, \mathrm{NH}(2), \mathrm{CH}(3)$, and $\mathrm{OH}$ functions. Dent Mater J 29, 438-445 (2010).

62. G. H. Nancollas, M. LoRe, L. Perez, C. Richardson, S. J. Zawacki, Mineral phases of calcium phosphate. Anat Rec 224, 234-241 (1989).

63. A. Linde, A. Lussi, M. A. Crenshaw, Mineral induction by immobilized polyanionic proteins. Calcif Tissue Int 44, 286-295 (1989).

64. C. L. Raggio, B. D. Boyan, A. L. Boskey, In vivo hydroxyapatite formation induced by lipids. J Bone Miner Res 1, 409-415 (1986).

65. C. A. Scotchford, S. Y. Ali, Magnesium whitlockite deposition in articular cartilage: a study of 80 specimens from 70 patients. Ann Rheum Dis 54, 339-344 (1995).

66. C. A. Scotchford, S. Y. Ali, Association of magnesium whitlockite crystals with lipid components of the extracellular matrix in human articular cartilage. Osteoarthritis Cartilage 5, 107-119 (1997).

67. C. A. Curcio, M. Johnson, M. Rudolf, J.-D. Huang, The oil spill in ageing Bruch's membrane. Br J Ophthalmol 95, 1638-1645 (2011). 
68. C. A. Curcio, Antecedents of soft drusen, the specific deposit of age-related macular degeneration, in the biology of human macula. Invest Ophthalmol Vis Sci 7/5/18 accepted, (2018).

69. W. Jahnen-Dechent, A. Heiss, C. Schafer, M. Ketteler, Fetuin-A regulation of calcified matrix metabolism. Circ Res 108, 1494-1509 (2011).

70. W. L. Lau, M. H. Festing, C. M. Giachelli, Phosphate and vascular calcification: Emerging role of the sodium-dependent phosphate co-transporter PiT-1. Thromb Haemost 104, 464-470 (2010).

71. E. Lederer, Regulation of serum phosphate. J Physiol 592, 3985-3995 (2014).

72. W. Jahnen-Dechent, M. Ketteler, Magnesium basics. Clin Kidney J 5, i3-i14 (2012).

73. A. M. Hofer, E. M. Brown, Extracellular calcium sensing and signalling. Nat Rev Mol Cell Biol 4, 530-538 (2003).

74. A. L. Lehninger, Mitochondria and calcium ion transport. Biochem J 119, 129-138 (1970).

75. S. Boonrungsiman, E. Gentleman, R. Carzaniga, N. D. Evans, D. W. McComb, A. E. Porter, M. M. Stevens, The role of intracellular calcium phosphate in osteoblast-mediated bone apatite formation. Proc Natl Acad Sci U S A 109, 14170-14175 (2012).

76. L. Galluzzi, K. Blomgren, G. Kroemer, Mitochondrial membrane permeabilization in neuronal injury. Nat Rev Neurosci 10, 481-494 (2009).

77. H. Kaneko, S. Dridi, V. Tarallo, B. D. Gelfand, B. J. Fowler, W. G. Cho, M. E. Kleinman, S. L. Ponicsan, W. W. Hauswirth, V. A. Chiodo, K. Kariko, J. W. Yoo, D. K. Lee, M. Hadziahmetovic, Y. Song, S. Misra, G. Chaudhuri, F. W. Buaas, R. E. Braun, D. R. Hinton, Q. Zhang, H. E. Grossniklaus, J. M. Provis, M. C. Madigan, A. H. Milam, N. L. Justice, R. J. Albuquerque, A. D. Blandford, S. Bogdanovich, Y. Hirano, J. Witta, E. Fuchs, D. R. Littman, B. K. Ambati, C. M. Rudin, M. M. Chong, P. Provost, J. F. Kugel, J. A. Goodrich, J. L. Dunaief, J. Z. Baffi, J. Ambati, DICER1 deficit induces Alu RNA toxicity in age-related macular degeneration. Nature 471, 325-330 (2011).

78. J. Feher, I. Kovacs, M. Artico, C. Cavallotti, A. Papale, C. Balacco Gabrieli, Mitochondrial alterations of retinal pigment epithelium in age-related macular degeneration. Neurobiology of Aging 27, 983-993 (2006).

79. M. R. Terluk, R. J. Kapphahn, L. M. Soukup, H. Gong, C. Gallardo, S. R. Montezuma, D. A. Ferrington, Investigating mitochondria as a target for treating age-related macular degeneration. J Neurosci 35, 7304-7311 (2015).

80. C. L. Nordgaard, P. P. Karunadharma, X. Feng, T. W. Olsen, D. A. Ferrington, Mitochondrial proteomics of the retinal pigment epithelium at progressive stages of age-related macular degeneration. Invest Ophthalmol Vis Sci 49, 2848-2855 (2008).

81. N. Kerur, S. Fukuda, D. Banerjee, Y. Kim, D. Fu, I. Apicella, A. Varshney, R. Yasuma, B. J. Fowler, E. Baghdasaryan, K. M. Marion, X. Huang, T. Yasuma, Y. Hirano, V. Serbulea, M. Ambati, V. L. Ambati, Y. Kajiwara, K. Ambati, S. Hirahara, A. Bastos-Carvalho, Y. Ogura, H. Terasaki, T. Oshika, K. B. Kim, D. R. Hinton, N. Leitinger, J. C. Cambier, J. D. Buxbaum, M. C. Kenney, S. M. Jazwinski, H. Nagai, I. Hara, A. P. West, K. A. Fitzgerald, S. R. Sadda, B. D. Gelfand, J. Ambati, cGAS drives noncanonical-inflammasome activation in age-related macular degeneration. Nat Med 24, 50-61 (2018).

82. K. J. Miyagishima, Q. Wan, B. Corneo, R. Sharma, M. R. Lotfi, N. C. Boles, F. Hua, A. Maminishkis, C. Zhang, T. Blenkinsop, V. Khristov, B. S. Jha, O. S. Memon, S. D'Souza, S. Temple, S. S. Miller, K. Bharti, In pursuit of authenticity: induced pluripotent stem cell-derived retinal pigment epithelium for clinical applications. Stem Cells Transl Med 5, 1562-1574 (2016).

83. N. M. Gomez, W. Lu, J. C. Lim, K. Kiselyov, K. E. Campagno, Y. Grishchuk, S. A. Slaugenhaupt, B. A. Pfeffer, S. J. Fliesler, C. H. Mitchell, Robust lysosomal calcium signaling through channel TRPML1 is impaired by lysosomal lipid accumulation. FASEB J, (2017). 
84. B. R. Pattnaik, B. A. Hughes, Regulation of Kir channels in bovine retinal pigment epithelial cells by phosphatidylinositol 4,5-bisphosphate. Am J Physiol Cell Physiol 297, C1001-1011 (2009).

85. X. Zhang, B. A. Hughes, KCNQ and KCNE potassium channel subunit expression in bovine retinal pigment epithelium. Exp Eye Res 116, 424-432 (2013).

86. H. Gong, T. Amemiya, K. Takaya, Retinal changes in magnesium-deficient rats. Exp Eye Res 72, 23-32 (2001).

87. C. L. Kakigi, K. Singh, S. Y. Wang, W. T. Enanoria, S. C. Lin, Self-reported calcium supplementation and age-related macular degeneration. JAMA Ophthalmol 133, 746-754 (2015).

88. B. Gopinath, V. M. Flood, J. C. Louie, J. J. Wang, G. Burlutsky, E. Rochtchina, P. Mitchell, Consumption of dairy products and the 15-year incidence of age-related macular degeneration. Br J Nutr 111, 1673-1679 (2014).

89. R. Klein, B. E. Klein, S. C. Jensen, K. J. Cruickshanks, K. E. Lee, L. G. Danforth, S. C. Tomany, Medication use and the 5-year incidence of early age-related maculopathy: the Beaver Dam Eye Study. Arch Ophthalmol 119, 1354-1359. (2001).

90. F. L. Ferris, 3rd, C. P. Wilkinson, A. Bird, U. Chakravarthy, E. Chew, K. Csaky, S. R. Sadda, Clinical classification of age-related macular degeneration. Ophthalmology 120, 844-851 (2013).

91. M. Li, R. Dolz-Marco, J. D. Messinger, L. Wang, R. M. Feist, C. A. Girkin, S. Gattoussi, D. Ferrara, C. A. Curcio, K. B. Freund, Clinicopathologic correlation of anti-vascular endothelial growth factortreated type 3 neovascularization in age-related macular degeneration. Ophthalmology 125, 276-287 (2018). 
Acknowledgments: The authors thank Drs. Richard A. Martin,Owen Addison; Alan C. Bird and Jonathan Knowles for their help and advice.

Funding: The research was supported by the Bill Brown Charitable Trust Senior Research Fellowship, Moorfields Eye Hospital Special Trustees and the European Union's Horizon 2020 research and innovation programme under grant agreement No 634479 for the "Eye-Risk" project (I.L.). Some of the tissues for this project was provided by the University College London Institute of Ophthalmology and Moorfields Eye Hospital Eye Tissue Repository supported by funding from the National Institute for Health Research. The Project MACULA website and the recovery of human donor eyes for research was supported by the National Institutes of Health (grant no.: R01EY06019, P30EY003039); the EyeSight Foundation of Alabama; the International Retinal Research Foundation; the Edward N. and Della L. Thome Foundation; the Arnold and Mabel Beckman Initiative for Macular Research; and Research to Prevent Blindness, Inc, New York, New York. Diamond Light Source (Harwell Science and Innovation Campus, Didcot, Oxfordshire OX11 ODE, UK) provided access to Beamline I18. The TOF-SIMS analysis was supported by the Engineering and Physical Sciences Research Council, United Kingdom (Grant EP/H006060/1) and by the Natural Environment Research Council, United Kingdom (Grant NE/J013382/1).

\section{Author contributions}

AT, multimodal imaging and analysis, cohort 1; MGP, IL, SF, SB, ET, EPM, mineralomics; ML, JDM, CAC, imaging-histology correlations; JL, MGN, SRS, patients and analysis for cohort 2; RDM, KBF patients for cohort 1; AP, MGP, IL, SRS, CAC; drafted manuscript; all authors, revised manuscript; IL, KBF, CAC, scientific direction. 


\section{Competing interests}

M. Li received research support from Hoffman LaRoche. K. B. Freund is a consultant to Genentech, Bayer HealthCare, Optovue, ThromboGenics, Ohr Pharmaceutical, and Heidelberg Engineering (honorarium for each). R. Dolz-Marzo receives research support from Alcon, Genentech, Heidelberg Engineering, Novartis and Roche. C.A. Curcio received research support from Hoffman LaRoche and Heidelberg Engineering. Srinivas R. Sadda is a consultant for Optos, Carl Zeiss Meditec, Centervue, Heidelberg Engineering, Allergan, Roche, Novartis, Iconic, Thrombogenics and received research support from Optos, Carl Zeiss Meditec, Allergan, Genentech. I. Lengyel receives unrestricted research support from Optos.

Material availability: All the data are present in the main manuscript or in the supplementary data 


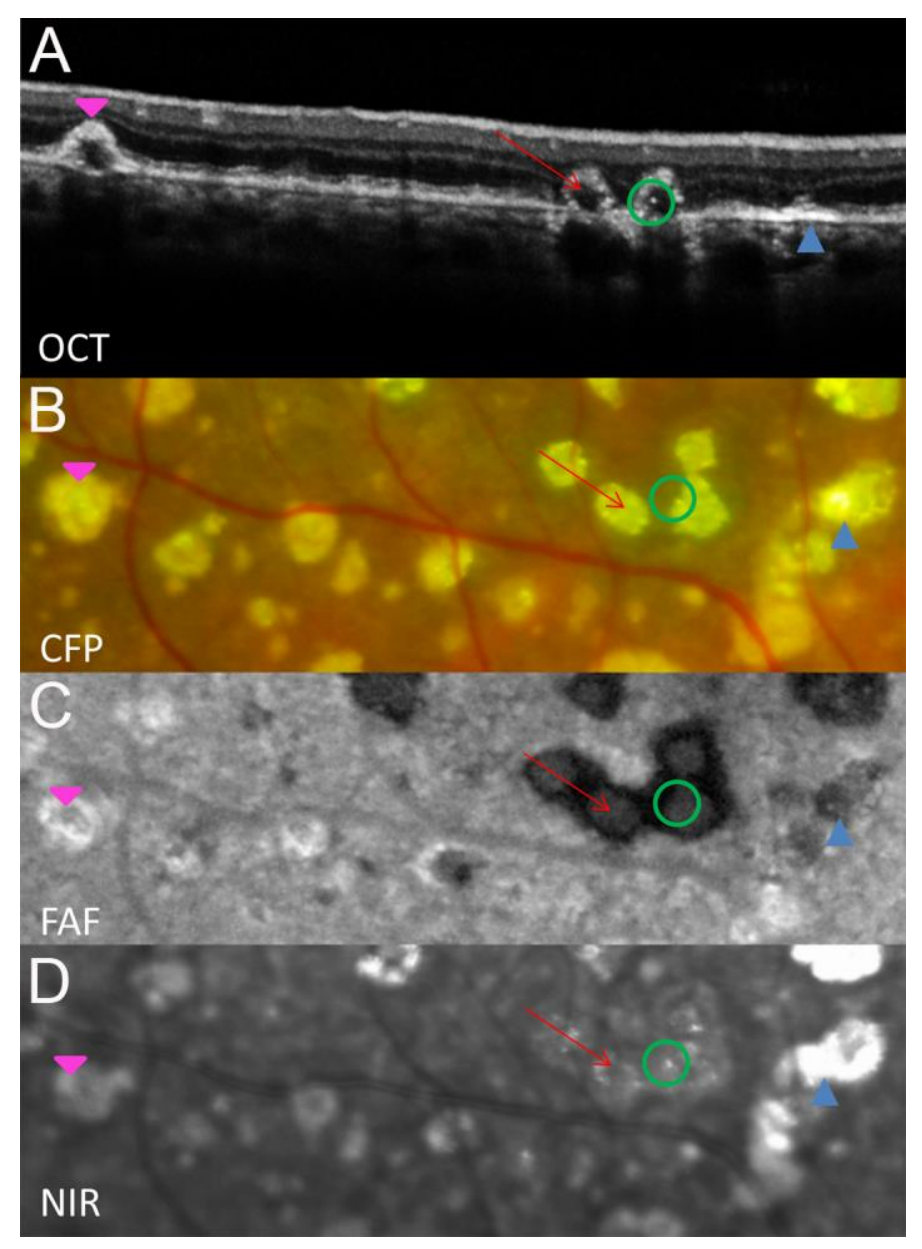

Figure 1: Multi-modal imaging of three types of calcified structures associated with advanced AMD. Heterogeneous internal reflectivity in drusen (HIRD), reflective dots, and plaques, seen on (A) optical coherence tomography (OCT), (B) color fundus photography (CFP), (C) fundus autofluorescence (FAF) and (D) near-infrared imaging (NIR). HIRD with a hyporeflective core (red arrow) and a hyperreflective cap (pink arrowhead), hyperreflective dots (green circle), and a hyperreflective plaque within Bruch's membrane (blue arrowhead) are indicated. 

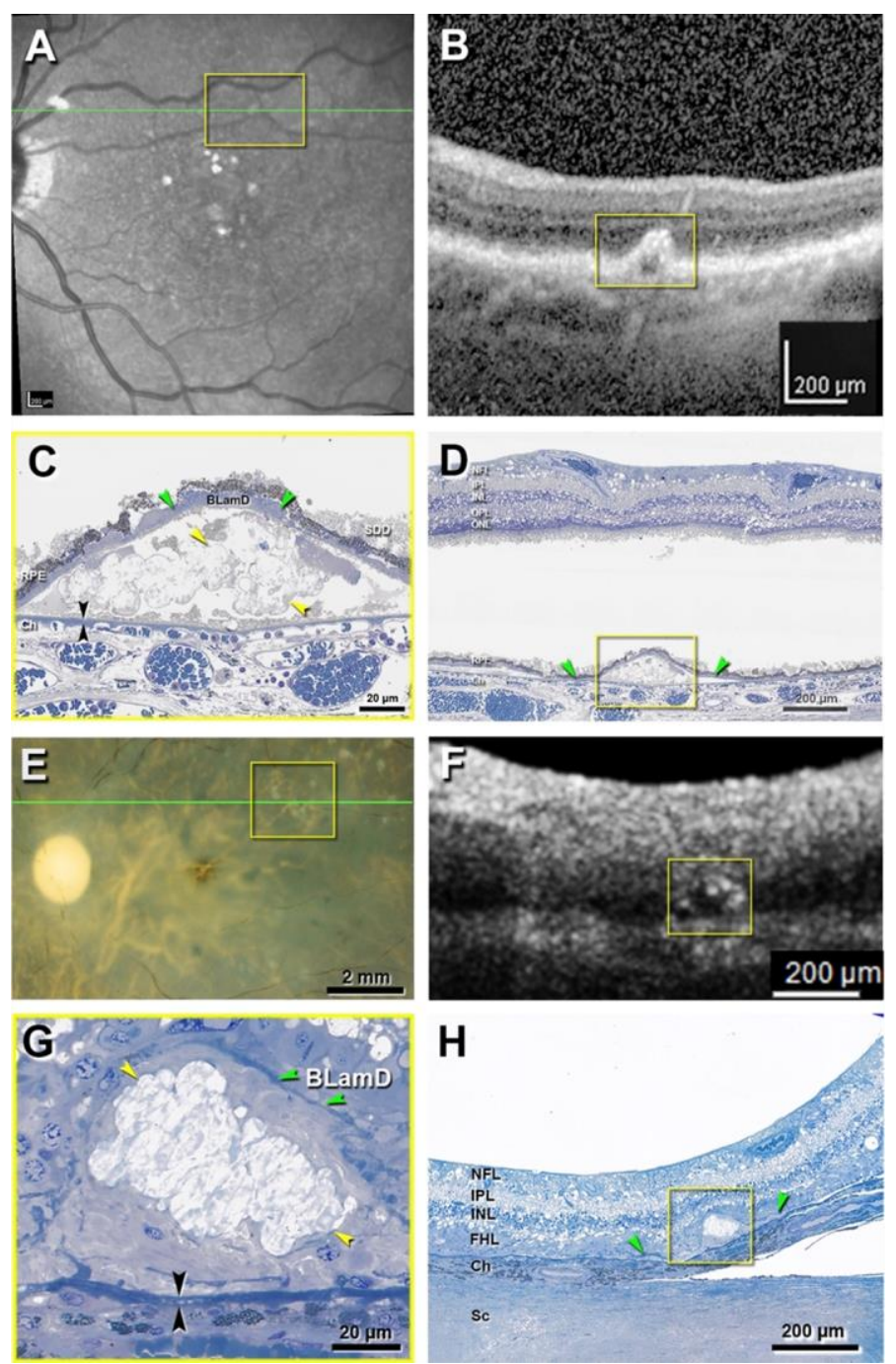

Figure 2: Imaging of heterogeneous internal reflectivity within drusen (HIRD) by optical coherence tomography (OCT) and nodules by histology. A-D: Eye of an 86-year-old white female with geographic atrophy (GA) imaged in vivo 4 months before death. A. NIR image shows translucent large drusen. Green line, level of OCT scan in panel B. Yellow frame, druse on panel B-D. B. OCT image showing HIRD (yellow frame). C. Druse corresponding to the HIRD. Large refractile nodules are surrounded by lipid-rich soft druse material (gray). SDD, subretinal drusenoid deposits. D. Panoramic light microscopy. The HIRD of panel B and the druse are at the same distance from the optic nerve head, as determined by comparing corresponding OCT scans and histology at the same dimensions. E-H. Eye of a 94-year-old 
white female with GA, imaged ex vivo. E. Color fundus photography shows refractile drusen in the superior temporal quadrant. Green line, level of OCT scan in panel F. F. Yellow frame denotes an HIRD. G. Calcific nodules are surrounded by processes of Müller cells. Overlying BLamD is thin and fragmented. H. Context of calcified druse, showing degeneration of outer retina including gliotic Henle fiber layer and absent photoreceptors. Submicrometer epoxy resin sections of OTAP-post-fixed specimens, toluidine blue stain. Separation of retina from RPE (B) and choroid from sclera $(\mathrm{H})$ is artifactual. NFL, nerve fiber layer; IPL, inner plexiform layer; INL, inner nuclear layer; HFL, Henle fiber layer; ONL, outer nuclear layer; BLamD, basal laminar deposit (a thickening of basement membrane material between the RPE and its basement lamina); Ch, choroid; Sc, sclera. Yellow arrowheads, calcific nodules; green arrowheads, BLamD; Black arrowheads, Bruch's membrane. 

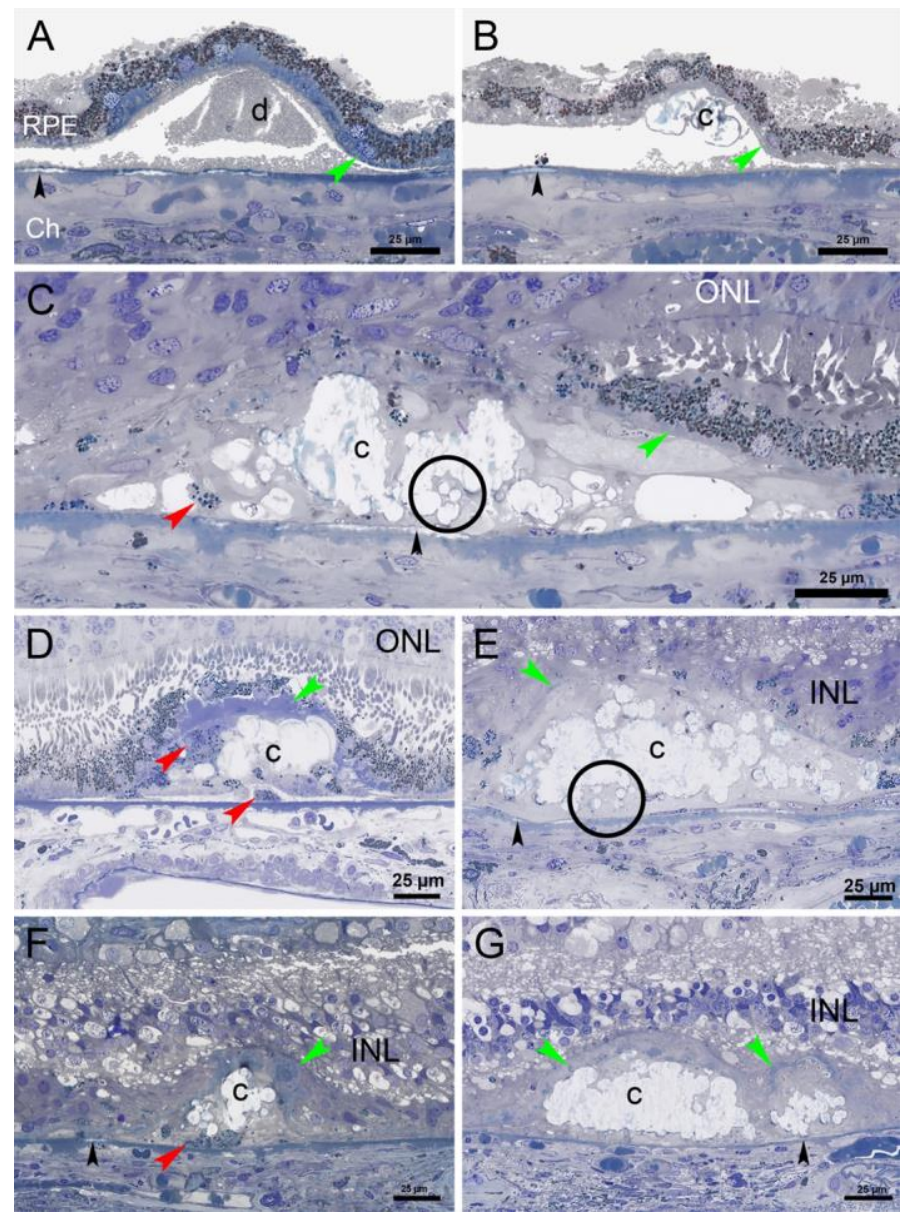

Figure 3: Histological variants of calcific nodule formation and RPE degeneration in

geographic atrophy. A. Small soft druse (d) containing lipoprotein-derived debris (artifactually fractured) and intact overlying RPE. B. Small soft druse with partial contents, refractile nodules, and intact overlying RPE. C. Calcific nodules and spherules and RPE-derived granule aggregates, with partial covering of RPE and photoreceptors, and lacking BLamD. D. Druse with calcific nodules and nucleated 'subducted' RPE with thick overlying BLamD and nearly complete coverage by RPE. E. Calcific nodules with very thin BLamD and no RPE. F. Calcific nodules with thin BLamD and 'subducted' RPE. G,H. Calcific nodules are found with thin overlying BLamD. Submicrometer epoxy resin sections of OTAP-post-fixed specimens, toluidine blue stain. INL, inner nuclear layer; ONL, outer nuclear layer; RPE, retinal pigment epithelium; green arrowheads, basal laminar deposit (BLamD); c, calcific nodule; black circle, calcific 
spherules; black arrowheads, calcification within Bruch's membrane; red arrowheads, RPE/ RPE derived material as indicated; Ch, choroid. 


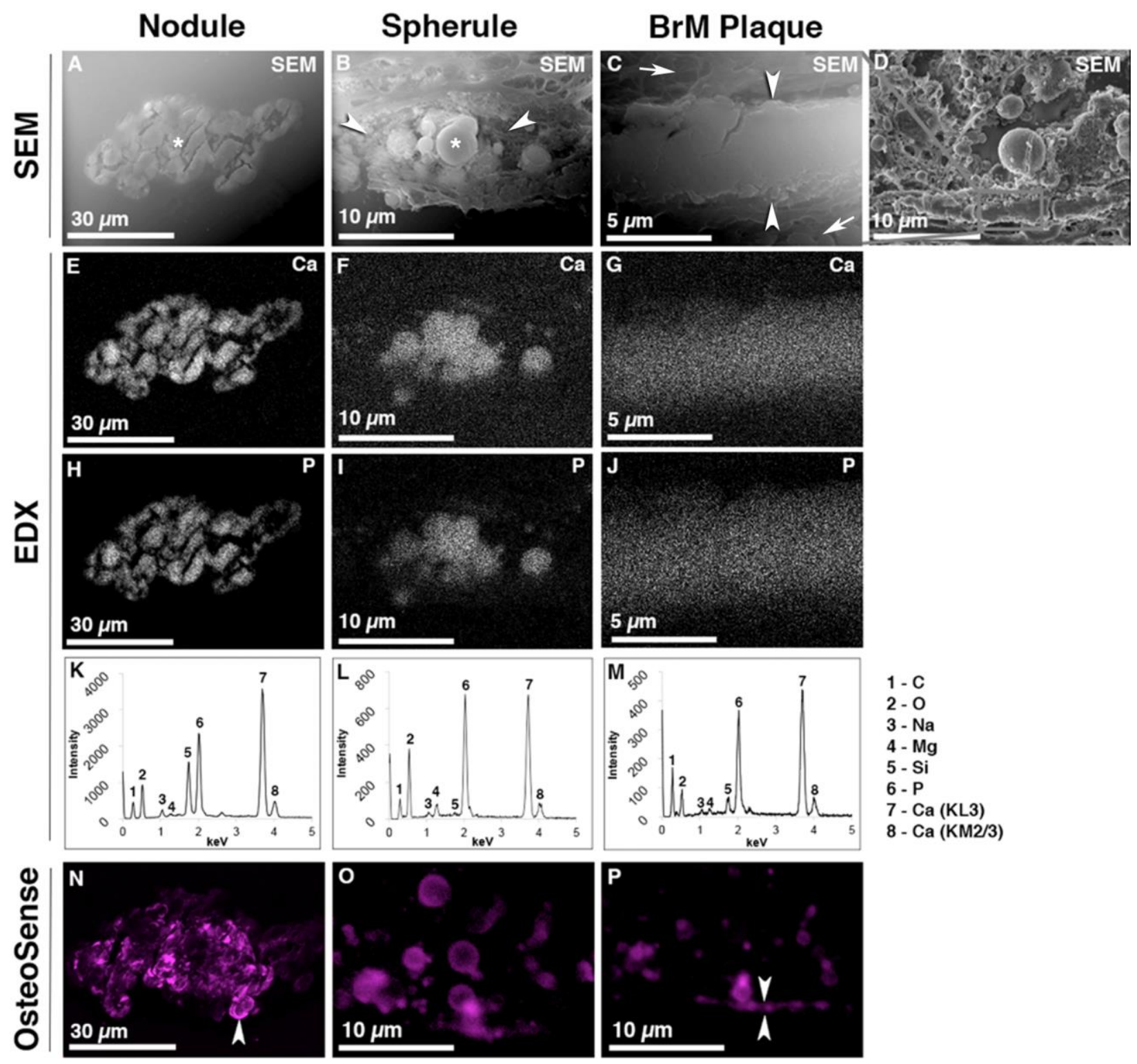

Figure 4: Scanning electron microscopy and energy dispersive x-ray spectroscopy of nodules, spherules and plaques. A-D High-magnification electron micrographs of calcific lesions. A. An isolated nodule (asterisk) is composed of lobed units $\sim 1-5 \mu \mathrm{m}$ in diameter. Cracks present on the nodule surface were formed during sectioning. B. Spherules (asterisk) approximately $0.5-5.0 \mu \mathrm{m}$ in diameter were located between the basal lamina of the RPE and the inner collagenous layer of BrM, along with extracellular material (arrowheads). C. Plaques (arrowheads), tens of microns in length and with cracks suggestive of mineralization, appeared 
visually similar to non-mineralized BrM. Arrows indicate surrounding tissues. E-J. Elemental maps of nodules, spherules and plaques generated using energy dispersive x-ray spectroscopy (EDX). E-G. X-ray emissions maps specific to calcium. H-J. X-ray emissions map specific to phosphate. K-M. Representative EDX spectra of X-ray emissionsfor nodules, spherules and plaques. N-P. Hydroxyapatite-specific staining confirmed the presence of apatite in nodules, spherules and plaques (arrowheads delimit the BrM). 

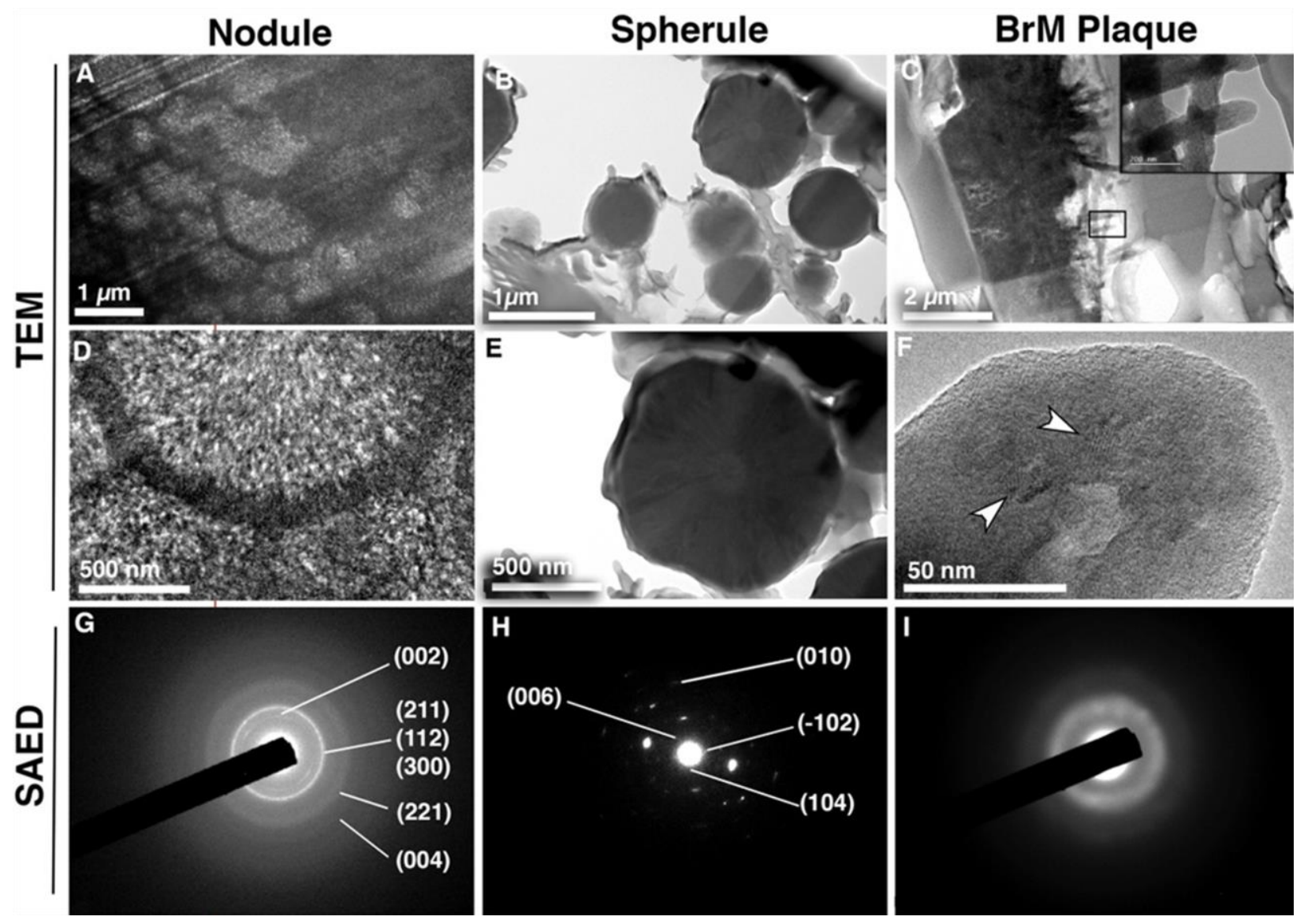

Figure 5: Transmission electron microscopy and selected area electron diffraction of

nodules, spherules and plaques. A-C. Low magnification electron micrographs of nodules, spherules and plaques. A. Nodules were composed of multiple sub-units (lobes) 1-20 $\mu \mathrm{m}$ in diameter. B. Spherules 0.5-5 $\mu \mathrm{m}$ in diameter exhibited increased electron density. C. Plaques exhibited increased electron density and appeared crossed over and fibrous (inset image). D-F. High-magnification electron micrographs of calcific lesions associated with AMD. D. A single "lobe" sub-unit of a nodule. Each lobe has an electron dense crust and a less electron dense core. E. Spherules displayed a heterogeneous structure; needle crystal-like structures formed a shell surrounding a less electron dense core. F. High-resolution micrograph of a plaque. White arrowheads indicate regions where the lattice is visible. G-I. Selected area electron diffraction of nodules, spherules, and plaques. A typical diffraction pattern obtained from each lesion is shown. Table S2 details additional reflexions identified by SAED but not indicated on figures. G. 
Nodules were indexed to HAP. A sharp diffraction ring for (002) was present, whilst a single diffuse ring was present for reflexions (211), (112) and (300). Rings characteristic of (221) and (004) were also observed. Diffraction patterns for the crust and the core were similar. H. The mineral component of spherules was identified as Whitlockite. Zone Axes (010) of Whitlockite was identified with vector points for (-102), (006) and (104). I. Diffraction patterns obtained for BrM plaques produced a diffuse ring characteristic of apatite. 